\title{
Sobre béroes y tumbas, novela del siglo
}

\begin{abstract}
A sí encabeza Günther W. Lorenz,' en Die Welt der Literatur, su A estudio sobre la segunda novela del argentino Ernesto Sábato. Lorenz califica tan altamente esta obra porque considera que ella es "un testimonio sumamente asombroso de nuestro tiempo" y "un hito que señala rumbos hacia el porvenir de la prosa del pensamiento científico". ${ }^{2}$ La obra de Sábato es una forma literaria intermedia entre el ensayo y la novela; en su mayor parte se compone de estudios científicos, episodios político-históricos, reflexiones sociológicas e indagaciones sobre la moral. Para el entusiasta crítico alemán representa la realización de dos vaticinios tamosos; el de Hegel, quien estableció que con el triunfo de la razón la literatura se convertirá en prosa científica, y el pronóstico crociano según el cual la literatura del futuro sería el ensayo y el compendio científico.

Sobre héroes y tumbas se destaca, además, como obra de gran valor artístico y humano. El empleo de diferentes técnicas novelísticas y modos elocutivos, la intercalación de un episodio histórico y la inclusión del "Informe sobre ciegos" no destruyen la unidad de la obra y aumentan notablemente el interés del lector. Sin embargo, la forma lograda de una obra literaria no sería un hecho tan significativo si el contenido no reflejase la condición humana de un país y del mundo en general. $Y$ : es precisamente este aspecto de la novela el que otorga a Sábato un puesto tan notorio entre los escritores actuales. A través de un detallado análisis de la realidad argentina no sólo llega a determinar lo que es lo nacional en un país compuesto de mezcla de nacionalidades, sino que también plantea los problemas del hombre moderno y se atreve a indicar una válvula de escape por la cual es posible disipar la acumulada presión de la angustia que agobia al mundo civilizado. De las experiencias

El señor Lorenz es el crítico de literatura hispanoamericana para el suplemento literario del prestigioso periódico alemán Die Welt, de Hamburgo. (2 "Ausdruck eines grossen Zorns," Die Welt der Literatur, 13 de abril, 1967. Todas las traducciones son mías.
\end{abstract}


humanas del pasado y del presente forja una nueva realidad para el futuro: la realidad de la esperanza escéptica que, aunque indisolublemente unida a la realidad argentina, se convierte en la descripción ontológica de nuestro mundo y de nuestro tiempo.

El señor Lorenz no disimula que para un europeo es sorprendente que la novela "cumbre" de esta orientación científica haya venido de la América Latina, zona cultural que, para los mismos escritores de este continente, es una región fronteriza de la civilización europea, una tierra de nadie. Sin embargo, el hecho de que una joven nación produzca una novela "revolucionaria" ya no debe sorprender a nadie, puesto que esto ha ocurrido repetidas veces en la historia de la literatura occidental. Dos casos ejemplates son el werther de Goethe y Crimen y castigo de Dostoievsky. En el siglo xvII, cuando Alemania, como país literario, ocupaba una posición muy inferior en relación con Francia e Inglaterra, apareció el Werther e introdujo una nueva sensibilidad que prevaleció sobre todas las jóvenes generaciones de escritores europeos. Un siglo más tarde, de la Rusia entonces desconocida y que apenas había empezado a desatrollàr una literatura nacional, vino Raskolnikof y triunfó como nuevo tipo humano porque encarnaba todos los problemas del mundo civilizado. Según Georg Lukács, estas obras aparecieron de improviso y en forma inesperada "de un país subdesarrollado" y produjeron un impacto indeleble en la historia de la cultura occidental, planteando "imaginativamente todos los problemas de la cultura humana". ${ }^{3}$

Parece que en un país en busca del orden, de valores, de una renlidad que sea otra que la cotidiana, se puede penetrar más hondamente en la problemática con que se enfrenta el mundo civilizado. La Rusia del siglo pasado, con intelectuales que sentían su contemporaneidad con los europeos occidentales, of rece el mejor ejemplo. En la época de Dostoievsky, la sociedad rusa apenas empezaba a transformarse y, tal vez por esa razón, los sueños napoleónicos de los jóvenes eran más apasionados y más violentos que los de sus contemporáneos del oeste. Se absorbía la cultura occidental con suma urgencia, y el esfuerzo de absorción produjo mucha tensión y ambivalencia en todos los niveles de la sociedad. Todo esto, y el hecho de que Rusia se encontraba en los límites de la civilización europea, hizo que sus escritores viesen más claramente las cuestiones vitales de su tiempo, sin que nada se interpusiese entre el problema y la pasión personal.

3 Georg Lukács, "Dostoievsky", en Dostoievsky: A collection of Critical Essays, ed. René Wellek (Englewood Cliffs, N. J.: Prentice Hall, Inc., 1962), p. 147. 
Casi un siglo más tarde, la Argentina se encuentra en una situación análoga. Como nación moderna comparte el destino del mundo civilizado que se ha vuelto completamente problemático. El hombre de nuestro tiempo es un desheredado; ha perdido su identidad y vive en un caos, en circunstancias catastróficas. Además, como explica Sábato, las condiciones de vida en la Argentina actual son mucho más complejas que las europeas. Los argentinos son un pueblo más angustiado, no sólo por razones de tiempo, sino también por razones de espacio:

...como integrantes de la civilización que sufre este cataclismo, tenemos un primer motivo de angustia: pero como pertenecientes a una de las líneas de fractura espacial de esa civilización, tenemos un segundo motivo, que es específicamente nuestro. Estamos en el fin de una civilización y en uno de sus confines. Sometidos a una doble quiebra en el tiempo y en el espacio, estamos destinados a una experiencia doblemente dramática... Y como si todavía eso fuera poco, no habíamos terminado de construit y definir una patria cuando el mundo que nos había dado origen comenzó a derrumbarse. Lo que significa que si ese mundo es un caos, nosotros lo somos a la segunda potencia."

La analogía que existe entre el clima intelectual de la Argentina actual y la Rusia hacia fines del siglo pasado puede extenderse, hasta cierto punto, a Sábato y Dostoievsky en lo que respecta a su búsqueda de valores para el mundo moderno. Ambos escritores no se conforman con el mero planteamiento de los problemas existenciales, sino que van más allá y tratan de proponer soluciones al dilema humano. El subsuelo es la primera obra de Dostoievsky que contiene todos los elementos importantes de sus grandes novelas. Se definen los problemas, pero no se resuelve nada. El hombre del subsuelo, prototipo del rebelde existencialista, al fin de la obra está condenado al limbo. Lo único que le queda son sus frustraciones, su rencor, su resentimiento, su soledad. Sin embargo, en la siguiente novela, Crimen $y$ castigo ( $y$ en las que seguirán a ésta), Dostoievsky formula la idea de que la desintegración que amenaza la personalidad moderna se puede contener si se acepta e] valor supremo del sufrimiento y la promesa cristiana de liberación.

De un modo parecido, en El tuinel de Sábato están esbozados ya muchos de los temas principales que se desartollarán y encontrarán solu-

4 Ernesto Sábato, El escritor y sus fantasmas, (Buenos Aires: Aguilar, 1963), pp. 40-41. 
ción en Sobre béroes y tumbas. La primera novela, no obstante, termina en una nota amarga y pesimista. El protagonista Castel, después de haber entrevisto la posibilidad de comunicación con otro ser, se da cuenta de que el acercamiento fue un engaño porque los seres humanos viven en túneles paralelos, permanentemente aislados el uno del otro. Sábato confiesa que no estuvo tranquilo hasta que no se publicó su segunda novela, porque sintió la necesidad de llegar a conclusiones distintas y más concretas.

Aunque Sobre béroes y tumbas es una obra compleja y es, como ha notado un crítico, "literatura para iniciados", 5 no resulta difícil entresacar las conclusiones afirmativas que ofrece el autor. El personaje principal. Fernando Vidal, rebelde y de actitud muy crítica contra sus propias flaquezas y las ajenas, reconoce que el mundo es una "canallocracia". De ahí su desesperación y su frenética búsqueda de la parte irreductible de su ser, la que trata de encontrar más allá del terror metafísico y la mezquindad. Por falta de orden y de moral en su propia vida, es destinado a morir, pero como buscó apasionadamente el verdadero sentido de la vida, dejó huellas muy hondas en el carácter de otras personas. Bruno, el comentarista filosófico de la novela, admite que Fernando "fue uno de esos individuos que, mientras viven, estimulan e impulsan con sus ideas y pasiones una cantidad de gente" y que el mismo Bruno le debe "momentos muy profundos" de su propia búsqueda. ${ }^{6}$

Resignado a causa de los muchos desengaños que ha sufrido en la vida, Bruno nos enseña, sin embargo, que al nihilismo se opone la esperanza, la cual, a pesar de todos los contratiempos que tiene que aguantar el hombre, y a causa de ellos, se mantiene en su corazón:

...no eran las ideas que salvaban al mundo, no era el intelecto ni la razón, sino todo lo contrario: aquellas insensatas esperanzas de los hombres, su furia persistente para sobrevivir, su anhelo de respirar mientras sea posible, su pequeño, testarudo y grotesco heroísmo de todos los días frente al infortunio. $Y$ si la angustia es la expresión de la Nada ¿no sería la esperanza la prueba de un Sentido Oculto de la Existencia, algo por lo cual vale la pena luchar? $Y$ siendo la esperanza más poderosa que la angustia... ¿no sería ese

5 Carmelina de Castellanos, "Aproximación a la abra de Ernesto Sábato", CHA, $\mathrm{N}^{\circ} 183$ (marzo, 1965), 491. p. 391.

6 Ernesto Sábato, Sobre béroes y tumbas, (Buenos Aires: Mirasol, 1963), 
Sentido Oculto el más verdadero, por decirlo así, que la famosa Nada??

A la idea de la esperanza, que por lo visto es una esperanza escéptica, se une el tema de la solidaridad humana. Como todos los hombres, en última instancia, comparten el mismo destino, el del sufrimiento y de la muerte, lo más importante en la vida es el sentido comunitario, de mutua ayuda y comprensión. El deseo de Bruno de ser cabo de bomberos es la expresión literaria de la idea de la solidaridad:

...porque entonces uno se sentiría que está entregado a algo comunitario, a algo en que uno realiza un esfuerzo para los demás, y además, en medio del peligro de la muerte... De modo que las penas son las penas de todos y las alegrías también, y el peligro es el peligro de todos. Saber, además, que uno puede y debe confiar en sus camaradas, en esos momentos límites de la vida, en esas zonas inciertas y vertiginosas en que la muerte nos enfrenta repentina y furiosamente, ellos, los camaradas lucharán contra ella, nos defenderán y sufrirán y esperarán por nosotros. ${ }^{8}$

Los valores humanos que Sábato busca no están en el tiempo futuro ni en el más allá: están dentro del hombre mismo y forman parte de su condición. Aunque las contradicciones de nuestro tiempo sean muchas, todos los hombres sienten la misma nostalgia de unidad y guardan la esperanza de una vida más honesta. Sobre béroes y tumbas ya no es novela existencialista, sino metafísica, porque trasciende la angustia, que es el término del pensamiento existencialista. $Y$ en el mundo que ha perdido su significado sagrado, la solidaridad humana es metafísica.

Tamara Holzapfel

University of New Mexico. Albuquerque, N. $M$.

7 Sobre béroes..., p. 201.

8 Sobre béroes..., p. 252. 
